\title{
ANÁLISE DA SEGURANÇA DO TRABALHO NOS CANTEIROS DE OBRAS DO MUNICÍPIO DE GUANAMBI-BA
}

\author{
Work Safety Analysis in the building sites from the city of Guanambi-BA
}

\author{
Carlos Eduardo Lopes FAGUNDES ${ }^{1}$, Harley Prado NEVES ${ }^{2}$, Thomas Leonardo Marques de Castro LEAL ${ }^{3}$ \\ Recebido em 06 de dezembro de 2019; aceito em 04 de abril de 2019; disponível on-line em 04 de junho de 2018.
}



PALAVRAS CHAVE:

Acidentes de trabalho;

Construção Civil;

Normas

Regulamentadoras;

Segurança do Trabalho.

\section{KEYWORDS:}

Work accidents;

Civil Construction;

Regulatory Standards;

Work Safety.

\section{* Contato com os autores:}

${ }^{1}$ e-mail: cadulopeseng.civil@gmail.com (C. E. L. Fagundes)

Bacharel em Eng. Civil pelo Centro Universitário UniFG e Pós-graduando em Engenharia de Segurança do Trabalho pela Unigrad.

2e-mail: harleyprado.eng@gmail.com (H. P. Neves )

Bacharel em Engenharia Civil pelo Centro Universitário UniFG,

${ }^{3}$ e-mail: thomasmdcl.fg@gmail.com (T. M. de C. Leal)

Especialista em Segurança do Trabalho pela Faculdade de Tecnologias e Ciências e docente do Centro Universitário UniFG.

\begin{abstract}
The main purpose of occupational safety is to ensure that it is carried out as intended, without danger to the workers concerned. Therefore, the objective of this research is to analyze the normative (non) compliance with the construction works of construction sites in the municipality of Guanambi-BA, with regard to worker safety. To , an exploratory survey was conducted at five construction sites in Guanambi between January and February 2018, with technical managers and employees, through the application of qualitative and quantitative questionnaires, in a total of 12 (twelve). interviewed. The data obtained were grouped according to aspects of the Regulatory Standards (NRs). The survey found irregular situations, such as the lack of the Environmental Risk Prevention Program (PPRA) and the Construction Conditions and Environment Program (PCMAT) in all construction sites, in addition to presenting irregular situations in the regards work at height, among others. However, some correct measures were also observed and in line with the regulatory norms, showing that the situation of the beds in the municipality of Guanambi-BA, although there is still much to do, there are potentials that can be harnessed and exploited.
\end{abstract}




\section{INTRODUÇÃO}

O trabalho sempre esteve presente na vida dos seres humanos e foi a partir dele que as civilizações se desenvolveram até chegarem ao nível atual (Ferreira; Peixoto, 2012).

Conforme De Faria, Graef e Sanches (2006), o desígnio principal da segurança do trabalho é garantir que este trabalho seja realizado da forma como estava previsto, sem fornecer perigo aos trabalhadores envolvidos, excluindo os riscos que possam levá-los a sofrer qualquer tipo de incidente ou acidente no ambiente laboral.

Acerca dos incidentes, Benite (2004) os define como um tipo de ocorrência sem danos pessoais, ou seja, que não resulta em morte, problemas de saúde, ferimentos, danos e outros prejuízos. À medida que, de acordo a legislação brasileira, por meio da Lei $n=8.213$, de 24 de julho de 1991, acidente de trabalho é caracterizado como aquele que ocasiona lesão corporal ou perturbação funcional, causando a morte ou a perda ou redução, permanente ou temporária, da capacidade de trabalhar, durante o exercício do trabalho (Brasil, 1991).

Segundo Camisassa (2015), os acidentes podem ser ocasionados de duas maneiras: por ato faltoso, que é quando o empregado, sem justificativa, se recusa a cumprir qualquer das obrigações conferidas a ele, como, por exemplo, as disposições legais ou usar o equipamento de proteção individual (EPI). E a outra maneira é por ato inseguro, que está relacionado à cultura do trabalhador, ou seja, à sua falta de conhecimento acerca da segurança, ou até mesmo por falta de segurança apropriada no ambiente de trabalho (Camisassa, 2015).

De acordo Vilela (2000), os acidentes de trabalho são influenciados por fatores relacionados à situação, como o maquinário utilizado, o local de trabalho, dentre outros. Sendo assim, elementos como a exigência de mais produção, as condições do maquinário e do ambiente (como presença de ruído e calor) e a realização de horas extras, são todos catalisadores que devem ser averiguados quando se pretende entender e evitar esses acidentes (Vilela, 2000).

A construção civil é um dos ramos que apresenta as piores condições de trabalho no mundo, sendo ela a responsável pela ocorrência de um dos maiores índices de acidentes de trabalho (Silveira et al., 2005).

O estudo da Segurança do Trabalho vem ganhando relevância nos últimos anos, porém, ainda é muito defasado e negligenciado o seu uso na prática, principalmente nos canteiros de obras, que são considerados um dos ambientes de trabalho mais propício a acidentes (Saurin; Ribeiro, 2000).

Fatores que dificultam a implantação e manutenção da segurança nos canteiros de obras, por exemplo, são os relacionados à falta de profissionais especializados dentro da empresa para atender e fiscalizar os requisitos normativos, o fato das instalações de produção ter caráter temporário, a mão de obra rotativa e a adoção de empresas terceirizadas (Costella; Junges; Pilz, 2014).

Em se tratando de um setor que demanda muito trabalho físico, a construção civil acaba acolhendo muitos trabalhadores sem instrução, que vêm a exercer atividades perigosas e desgastantes, sendo, portanto, a ocorrência de acidentes algo comum (Brasil, 2014).

De acordo a análise das estatísticas dos acidentes de trabalho na construção civil realizada pelo Informe da Previdência Social de 2014, constatou-se que entre 2008 e 2012, o total de acidentes no Brasil caiu 6,7\%, enquanto o total de acidentes no setor da construção civil aumentou 19\% (Brasil, 2014).

Essa participação crescente do setor nos acidentes de trabalho do Brasil mostrou que em 2008 os acidentes em canteiros de obras correspondiam a 6,9\% do total de acidentes no País, enquanto em 2012, passou a representar $8,9 \%$, evidenciando o peso desse setor na ocorrência de acidentes de trabalho (Brasil, 2014).

Essa pesquisa pode contribuir para os meios acadêmico e técnico, servindo de informativo, visando transmitir informações, como a existência e importância de se seguir as normas regulamentadoras sobre segurança do trabalho, e como isso pode acarretar na melhoria das condições laborais no munícipio de Guanambi-BA, além de sugerir modificações no âmbito da realidade em que se encontra o tema discutido, visando à melhoria da qualidade de vida dos empregados e na geração de um ambiente de trabalho mais seguro e isento às 
irresponsabilidades.

\section{OBJETIVO}

O objetivo dessa pesquisa é analisar o (des)cumprimento normativo diante das obras de construção civil de canteiros no município de Guanambi, no que se refere à segurança do trabalhador, através da aplicação de questionários com responsáveis técnicos e trabalhadores destes ambientes de trabalho.

\section{METODOLOGIA}

A pesquisa tem caráter exploratório, onde foram coletadas, por meio de aplicação de questionários, informações acerca da realidade da segurança do empregado nos canteiros de obras do município de Guanambi-BA. As perguntas foram baseadas nas Normas Regulamentadoras (NRs), de forma a verificar o quanto estão sendo cumpridas. Para isso, foram observadas as NR 1 Disposições Gerais, NR 5 - Comissão Interna de Prevenção de Acidentes, NR 6 - Equipamentos de Proteção Individual (EPI), NR 9 - Programa de Prevenção de Riscos Ambientais e NR 18 Condições e Meio Ambiente de Trabalho na Indústria da Construção.

Por se tratar de uma pesquisa com seres humanos, ela foi submetida, e, posteriormente, aprovada pelo Comitê de Ética em Pesquisa (CEP), com o seguinte número do parecer: 2.936.935.

Entrevistou-se 12 (doze) pessoas entre responsáveis técnicos e colaboradores de 5 (cinco) obras de pequeno e médio porte do município durante os meses de janeiro e fevereiro de 2018. Todas as obras visitadas são de pessoas físicas.

A pesquisa de campo foi direcionada através da aplicação de questionários de abordagem quantitativa. Os dados colhidos foram organizados de acordo aspectos das NRs, agrupando-os de forma homogênea. Inicialmente serão discutidos os resultados obtidos com os responsáveis técnicos pelas 5 (cinco) obras, sendo um deles responsável por 3 (três) obras e o outro por 2 (duas) de mesmas características e, posteriormente, serão discutidos os dados colhidos com os 10 (dez) trabalhadores das obras visitadas.

Foram realizadas 3 (três) visitas em cada canteiro de obras, sendo a primeira para reconhecimento do local, e do dia a dia de trabalho dos empregados. Na segunda visita, os pesquisadores observaram as relações entre o responsável técnico e os empregados, e, por fim, em uma terceira visita, quando os pesquisadores já tinham conhecimento do ambiente e os participantes se sentiam mais à vontade, começou-se a aplicação do questionário. Vale ressaltar que os participantes da pesquisa não foram informados da data da terceira visita dos pesquisadores, visando assim não haver coibição por parte do responsável técnico aos empregados.

A observação participante também foi uma das ferramentas para realização do trabalho proposto, uma vez que existe uma série de fenômenos de grande importância que não podem ser registrados por meio de perguntas ou em outros documentos. Com isso, além da aplicação dos questionários, os pesquisadores fizeram uso desse artifício, que proporcionou uma maior aproximação entre eles e o evento, possibilitando uma visão holística sobre o espaço analisado. Através dele, foi possível detectar e extrair informações além das perguntas do questionário, possibilitando assim, uma maior participação nas atividades de recolha de dados, tornando-se, portanto, instrumento de pesquisa.

\section{RESULTADOS E DISCUSSÃO}

\subsection{RESULTADOS OBTIDOS COM OS RESPONSÁVEIS TÉCNICOS}

Para coleta dos resultados, utilizou-se as variáveis "sim" e "não" com o objetivo de verificar o atendimento aos itens do questionário nos canteiros visitados.

\subsubsection{Aspectos da NR 1 - Disposições Gerais}


Referente à esta NR foram analisadas 4 (quatro) questões, esquematizadas na Figura 1, sendo, respectivamente, as seguintes:

1- A empresa elaborou o Programa de Condições e Meio Ambiente de Trabalho na Indústria da Construção (PCMAT) ou o Programa de Prevenção de Riscos Ambientais (PPRA)?

2- O empregador elaborou ordens de serviço, informando os procedimentos relativos à segurança no trabalho para os empregados, por meio de comunicados, cartazes, e-mails?

3- A empresa realizou exames médicos nos trabalhadores? E se sim, os resultados foram apresentados a eles?

4- A empresa já constatou casos de ato faltoso e/ou ato inseguro por parte dos trabalhadores?

Conforme o gráfico, os responsáveis técnicos pelas 5 (cinco) obras não elaboraram o Programa de Condições e Meio Ambiente do Trabalho na Indústria da Construção (PCMAT) para obras com mais de 20 (vinte) trabalhadores, como consta na NR 18, e nem o Programa de Prevenção de Riscos Ambientais (PPRA) nas obras com menos de 20 (vinte) trabalhadores, visto que, nesse tipo de obra o PCMAT não é obrigatório.

A título de comparação, em pesquisa realizada por De Mélo Filho, Rabbani e Barkokébas Júnior (2011), nenhuma das edificações visitadas (manutenção de edificações verticais) possuía disponíveis no canteiro de obras as documentações de PPRA e PCMAT, evidenciando que essa falta de iniciativa das empresas no campo da preservação da saúde e integridade física dos trabalhadores é uma realidade preocupante que se faz presente nesses ambientes de trabalho.

O segundo questionamento foi a respeito da elaboração de ordens de serviço, com vistas a informar os procedimentos relativos à segurança do trabalho para os empregados, por meio de comunicados, cartazes ou e-mails, no qual os responsáveis técnicos afirmaram ter realizado em $100 \%$ das obras visitadas, o que mostra uma relativa preocupação em manter o ambiente de trabalho seguro e isento às irresponsabilidades por parte dos trabalhadores, visto que houve uma preocupação em esclarecer sobre as medidas de segurança adotadas e que devem ser tomadas por eles durante a atividade laboral.

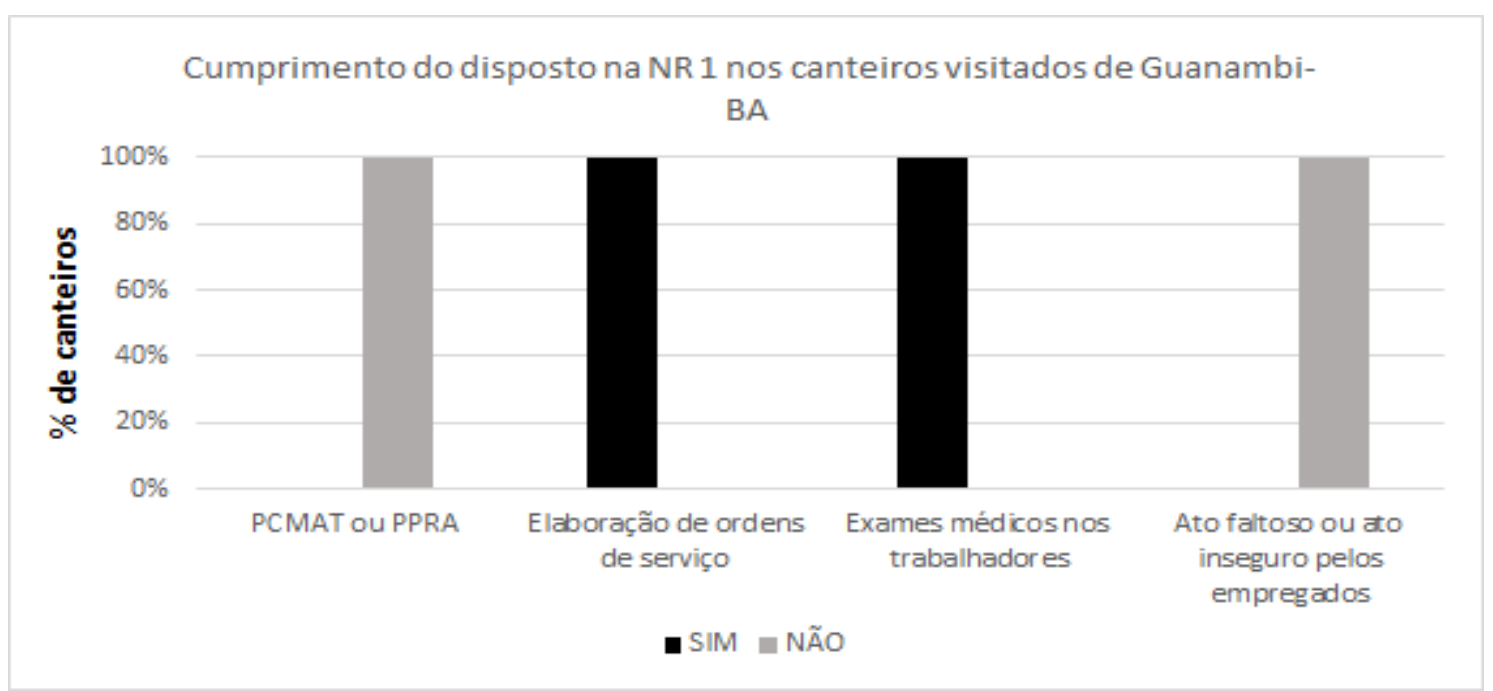

FIGURA 1: Aspectos sobre o cumprimento do disposto na NR 1 nos canteiros visitados do município de Guanambi-BA FONTE: Autoria própria 
Em seguida, os responsáveis técnicos foram questionados se haviam sido realizados exames médicos (admissionais e/ou periódicos) nos trabalhadores, e todas as respostas foram positivas, sendo que, foram feitos apenas exames admissionais e nenhum periódico.

Contrastando com os resultados obtidos, De Carvalho et al. (1998), em pesquisa realizada em edificações da microrregião do Cariri cearense (Triângulo Crajubar), constatou que de acordo 61\% dos entrevistados, a empresa não realizou exames ocupacionais, e dos que foram realizados quase a totalidade são apenas admissionais.

De acordo os dados, nas obras entrevistadas do município de Guanambi houve uma preocupação em realizar exames médicos de admissão, porém, não houve interesse na realização de exames periódicos, provavelmente devido ao caráter temporário desse ambiente de trabalho.

Por fim, no que diz respeito à NR 1 , os responsáveis técnicos afirmaram não ter percebido ato faltoso (recusa do cumprimento das obrigações) ou inseguro (falta de conhecimento acerca da segurança) por parte dos trabalhadores das cinco obras. Esses resultados mostram que além de terem uma boa relação no ambiente de trabalho, os trabalhadores também nutrem um certo conhecimento dos perigos que os rodeiam no desempenho de suas funções.

\subsubsection{Aspectos da NR 6 - Equipamento de Proteção Individual}

Referente à NR 6 foram analisadas 6 (seis) questões, esquematizadas na Figura 2, sendo, respectivamente, as seguintes:

1- A empresa adotou, primeiramente, medidas de proteção coletiva na obra, antes de empregar os EPIs?

2- A empresa se certificou que o EPI possui Certificado de Aprovação (aprovação para o seu uso)?

3- A empresa se certificou que o trabalhador cumprisse o uso dos EPIs?

4- A empresa se responsabiliza pela manutenção e higienização dos EPIs usados pelos trabalhadores?

5- Ao ser observada alguma irregularidade no EPI, o empregador tem ciência que deve comunicar ao Ministério do Trabalho e Emprego (MTE)?

6- O empregador adquiriu amostras do EPI, antes de comprá-lo, para que os trabalhadores pudessem verificar na prática se o mesmo é confortável ou não, se possui dificuldade para uso, etc.?

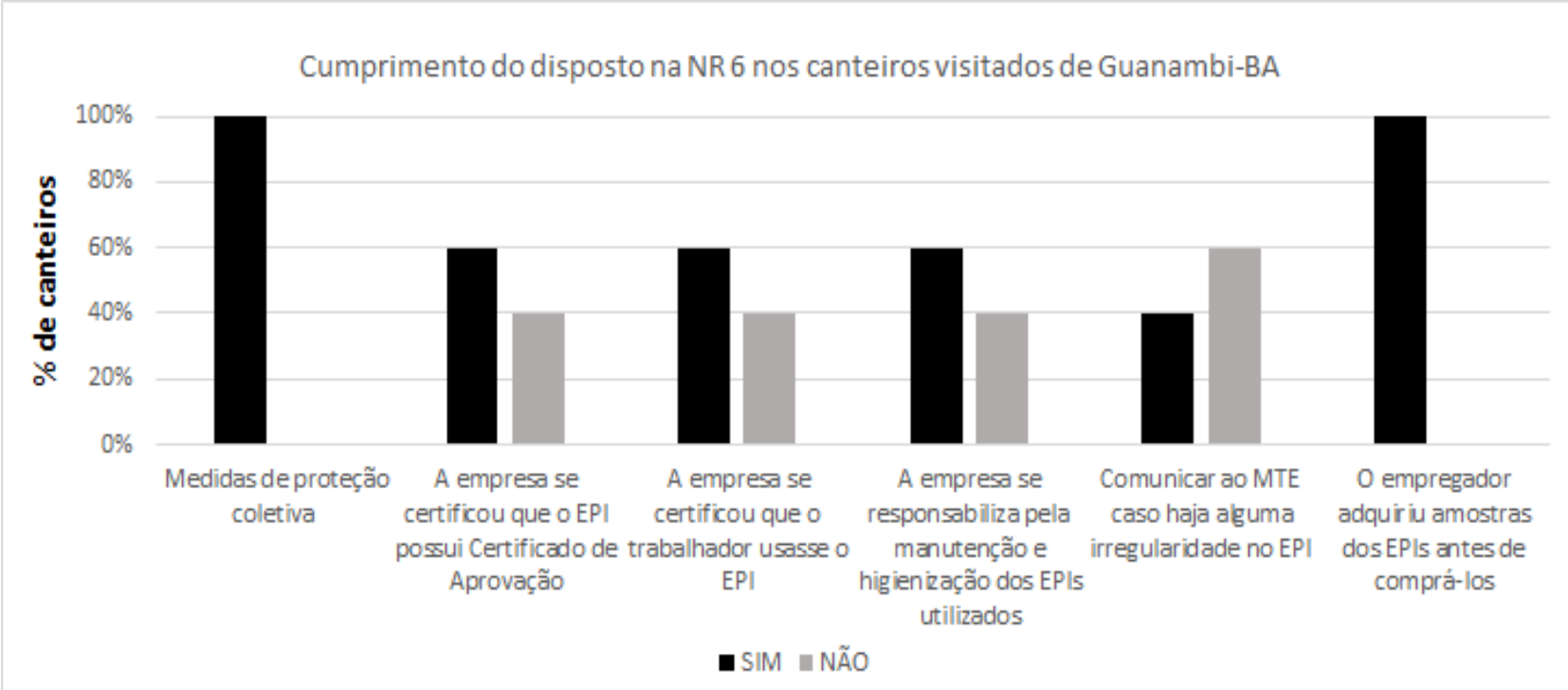

FIGURA 2: Aspectos sobre o cumprimento do disposto na NR 6 nos canteiros visitados do município de Guanambi-BA FONTE: Autoria própria 
Conforme a Figura 2, nas 5 (cinco) obras não adotaram-se medidas de proteção coletiva antes do emprego dos equipamentos de proteção individual (EPIs). A NR 9 - Programa de Prevenção de Riscos Ambientais (Brasil, 1978) disserta que antes de decidir pelo fornecimento do EPI, a empresa ou o empregador deve priorizar a adoção de medidas de proteção coletiva, e só quando estas forem tecnicamente inviáveis ou insuficientes, os EPIs deverão ser fornecidos.

Tais resultados evidenciam que os responsáveis técnicos não implantaram, previamente, as medidas de proteção coletiva nos canteiros de obras, optando, unicamente, pelo fornecimento dos equipamentos de proteção individual.

Sequencialmente, questionou-se a respeito da empresa ter se certificado de que os EPIs possuíam Certificado de Aprovação (CA), ou seja, aprovação para o seu uso, e constatou-se que em $60 \%$ dos canteiros visitados os responsáveis técnicos confirmaram a existência do CA nos EPIs fornecidos.

De acordo a NR 6 - Equipamento de Proteção Individual (Brasil, 1978), o EPI só poderá ser comercializado se possuir o Certificado de Aprovação, emitido pelo Ministério do Trabalho e Emprego (MTE).

Destarte, os dados evidenciam uma preocupação do responsável técnico das 3 (três) obras ao se atentar à certificação dos EPIs adquiridos, enquanto que, o responsável por $40 \%$ das obras entrevistadas alegou não ter conhecimento desse documento, e que por isso não o verificou junto aos EPIs.

O questionamento subsequente baseou-se na certificação do empregador em fazer cumprir o uso dos EPIs, e em $60 \%$ das obras isso aconteceu, mostrando uma preocupação quanto ao uso dos equipamentos pelos trabalhadores. $\mathrm{Em}$ contrapartida, em $40 \%$ das obras, os responsáveis técnicos não veem necessidade em cobrar o uso dos EPIs aos trabalhadores, importando-se apenas em fornecê-los.

Em seguida, os responsáveis técnicos foram questionados a respeito da sua responsabilização pela manutenção e higienização dos EPIs utilizados pelos trabalhadores, e em $60 \%$ das obras a resposta foi positiva, enquanto que no restante delas, o responsável técnico alegou acreditar que essa responsabilidade cabia aos trabalhadores, e por isso não realizava tais procedimentos.

Conforme a NR 6 - Equipamento de Proteção Individual (Brasil, 1978), uma das atribuições do empregador quanto ao EPI é responsabilizar-se pela sua higienização e manutenção periódica, evidenciando a falta de conhecimento em $40 \%$ das obras visitadas.

Adiante foi questionado se ao ser observada alguma irregularidade no EPI, o empregador teria ciência que deve comunicá-la ao Ministério do Trabalho e Emprego (MTE), e em $60 \%$ dos canteiros os responsáveis técnicos alegaram não ter conhecimento sobre tal fato, acreditando que teriam que recorrer ao fornecedor do equipamento.

Conforme Camisassa (2015), qualquer irregularidade observada no EPI, como fissuras em capacete para proteção contra impactos de objetos sobre o crânio, o empregador deve imediatamente comunicar ao MTE, de forma que sejam tomadas as devidas providências, como recolhimento das amostras do EPI e realização de novos testes, o que deixa evidente a falta de conhecimento dos responsáveis técnicos quanto à norma em relação a esse quesito.

Por fim, questionou-se acerca da aquisição de amostras de EPIs antes de comprá-los por parte dos empregadores, e em $100 \%$ das obras isso aconteceu, o que mostra uma preocupação por parte dos responsáveis técnicos quanto à qualidade do equipamento que será distribuído aos trabalhadores.

\subsubsection{Treinamento dos trabalhadores}

Referente ao treinamento dos trabalhadores foram analisadas 2 (duas) questões, esquematizadas na Figura 3, sendo, respectivamente, as seguintes:

1- Os trabalhadores da obra foram submetidos a treinamento admissional e/ou periódico relativo à segurança do trabalho?

2- A empresa realizou treinamentos sobre o uso, guarda e conservação do EPI? 




FIGURA 3: Aspectos sobre o cumprimento da realização de treinamentos dos trabalhadores nos canteiros visitados do município de Guanambi-BA

FONTE: Autoria própria

Como disposto na figura, em $60 \%$ das obras houve treinamento admissional e periódico dos trabalhadores, enquanto o restante (40\%) não realizou esses treinamentos antes do trabalhador iniciar suas atividades, sendo a realização dos dois treinamentos obrigação do empregador, conforme a NR 18 - Condições e Meio Ambiente de Trabalho na Indústria da Construção.

Quanto ao treinamento do uso adequado, guarda e conservação de EPI, também obrigação do empregador, conforme NR 6, foi realizado em $60 \%$ das obras, enquanto nas restantes $(40 \%)$ não houve a realização de tal treinamento.

Questionado sobre como era feito o planejamento desses treinamentos, o responsável técnico por $60 \%$ das obras afirmou que não os planeja, apenas segue as exigências da NR 18 para os treinamentos admissional e periódico e da NR 6 para os de EPI, além de não possuir infraestrutura adequada (salas e materiais didáticos) nos canteiros para a realização dos treinamentos.

O responsável por $40 \%$ das obras que não realizam os treinamentos alegou falta de tempo, pois possui uma rotina de trabalho muito sobrecarregada, não conseguindo se atentar às questões relativas a treinamentos e comunicação com os trabalhadores, embora reconheça a importância desses procedimentos e que deveria atentar-se mais a eles.

\subsubsection{Aspectos sobre áreas de vivência}

Referente a áreas de vivência foram analisadas 3 (três) questões, esquematizadas na Figura 4, sendo, respectivamente, as seguintes:

1- No canteiro de obras há áreas de vivência? Se sim, quais?

2- É fornecida água potável, filtrada e fresca para os trabalhadores? Se sim, por meio de bebedouros?

3- As instalações sanitárias obedecem as dimensões mínimas determinadas em norma?

Inicialmente questionou-se a existência de áreas de vivência nos canteiros, tendo em todos resposta afirmativa. De acordo a NR 18, tais ambientes de trabalho devem dispô-las e serem mantidas em perfeito estado de conservação, higiene e limpeza (Brasil, 1978). As áreas de vivência analisadas foram: vestiário, local para refeições, cozinha e instalações sanitárias. Além disso, também foi questionado se havia bebedouro para fornecimento de água potável nos canteiros.

Acerca dos vestiários, em $60 \%$ dos canteiros eles se fizeram presentes, enquanto 0 restante não os possuíam. Segundo a NR 18, deve dispor de vestiário todo canteiro de obra em que os trabalhadores não residem nele (Brasil, 1978), o que acontece em todos os canteiros visitados. Sendo assim, os trabalhadores daqueles que não 
possuem tal área de vivência realizam a troca de vestuário nas instalações sanitárias, visto que não há local adequado para tal.

Em se tratando de refeitório, todos os canteiros visitados possuem esta área de vivência. Eles apresentaram adequação com os requisitos da NR 18, porém, também servem como local de descanso dos trabalhadores no horário de almoço.

Em relação à cozinha, $60 \%$ dos canteiros têm preparo de refeições na obra, sendo assim eles possuem tal área de vivência em condições condizentes com o disposto na NR 18. Por outro lado, no restante dos canteiros visitados não há preparo de refeições, e consequentemente, não possuem cozinha. Sendo assim, os trabalhadores que não residem na cidade devem trazer seu almoço de casa, porém, os canteiros não possuem local exclusivo para o aquecimento de refeições, algo que, de acordo a NR 18, independe da cozinha e deve existir em todo canteiro de obra (Brasil, 1978).

Quanto à existência de bebedouros, todos os canteiros de obras os possuem, fornecendo água potável para os trabalhadores, conforme os padrões da NR 18. A título de comparação, uma pesquisa feita por Assmann (2015), em obras de edificações multifamiliares localizadas no município de Santa Rosa-RS, constatou-se que em todos os canteiros visitados era fornecida água potável aos trabalhadores, porém, em apenas 50\% deles era por meio de bebedouros, sendo que no restante, a disponibilização de água se dava por meio de garrafas armazenadas junto as geladeiras localizadas no refeitório. Sendo assim, os canteiros visitados em Guanambi cumprem o disposto na NR 18 quanto a esse item ao fornecer água potável aos trabalhadores através de bebedouros.

Com relação as instalações sanitárias, todas possuem dimensões normatizadas, como o pé-direito mínimo de 2,50m, conforme a NR 18 , porém, nenhum dos canteiros visitados possuíam mictório, um dos itens básicos, conforme a norma vigente. Os canteiros que continham chuveiros não dispunham de água quente, e as instalações sanitárias, no geral, estavam em baixo estado de conservação e higiene.

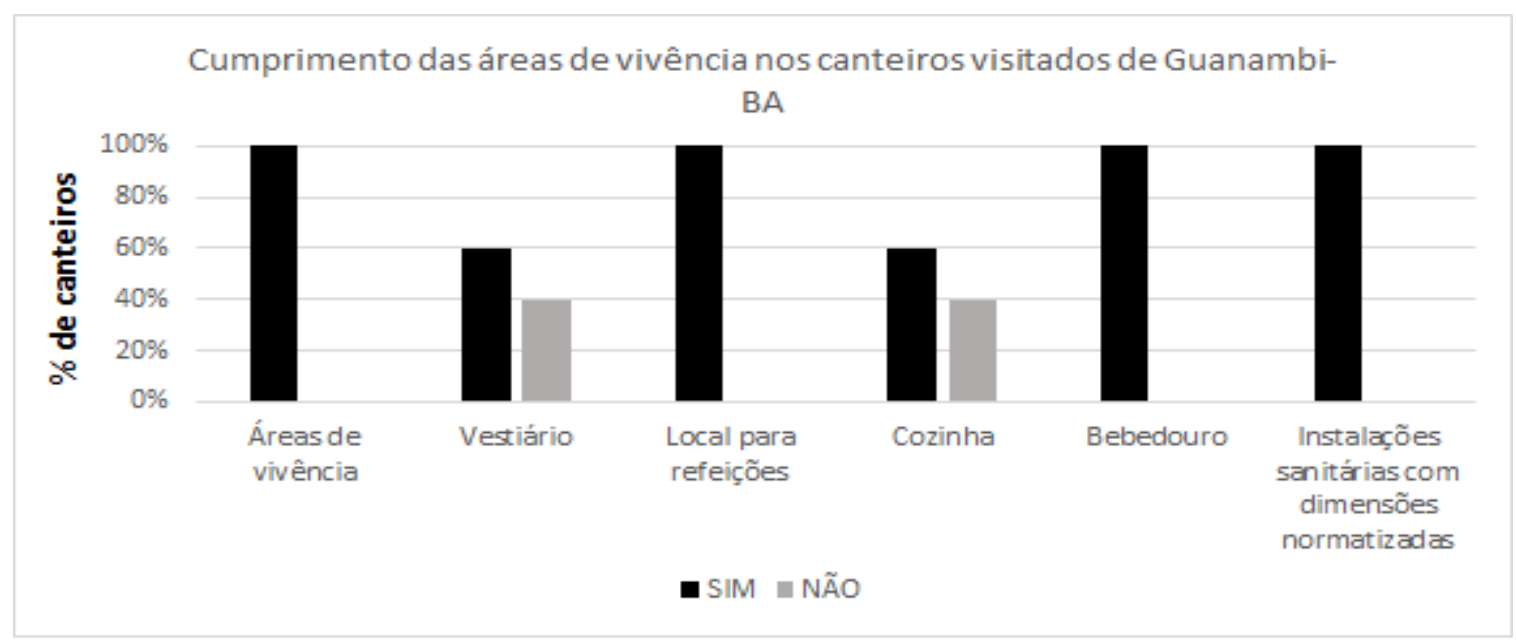

FIGURA 4: Aspectos sobre o cumprimento das áreas de vivência nos canteiros visitados do município de Guanambi-BA FONTE: Autoria própria 


\subsubsection{Trabalho em altura}

Referente ao trabalho em altura foram analisadas 4 (quatro) questões, esquematizadas na Figura 5, sendo, respectivamente, as seguintes:

1- Em locais onde há risco de queda de altura, existe a proteção coletiva guarda-corpo/rodapé?

2- Em locais onde há risco de queda de altura, existe a proteção coletiva contra queda de materiais (apara-lixo ou bandejão)?

3- O perímetro da construção do edifício está fechado com tela para oferecer barreira de proteção contra materiais ou ferramentas?

4- Em locais onde há risco de queda de altura, existe trabalhadores trabalhando em andaimes, devidamente protegidos?

Com relação à proteção coletiva contra quedas de altura, em sistema de guardacorpo e rodapé, todos os canteiros visitados atendem tal requisito, o que evidencia o comprometimento das obras visitadas quanto à segurança dos trabalhadores, no que concerne a este critério.

Em contrapartida, ao questionar sobre a existência de proteção contra queda de materiais, chamada de plataforma de proteção, também conhecida como "apara-lixo" ou "bandejão", 60\% dos canteiros visitados não a implantaram, colocando em risco trabalhadores que transitam pela obra, podendo os funcionários serem atingidos por algum material.

Em seguida, questionou-se a existência de tela para proteção contra projeção de materiais e ferramentas, e em todas as obras ela se fez presente. Porém, de acordo a NR 18, em seu item 18.13.9, o perímetro da construção deve ser fechado com tela acompanhando a(s) plataforma (s) de proteção, ou seja, da mesma forma que as plataformas devem ser instaladas ao longo de todo perímetro da edificação, a tela também deve circundá-la (Brasil, 1978).

Portanto, nos canteiros que implantaram a tela, mas não dispunham de plataforma de proteção (60\%), ainda assim encontraram-se em não conformidade com a norma, visto que ambas as medidas de proteção coletiva deveriam ser implantadas conjuntamente.

5- Por fim, questionou-se se os trabalhadores desempenhavam suas funções em andaimes devidamente protegidos, e em $60 \%$ dos canteiros isso não ocorria, reforçando o fato de que, no que diz respeito ao trabalho em altura, a maioria dos canteiros visitados não atendem o disposto na NR 18.

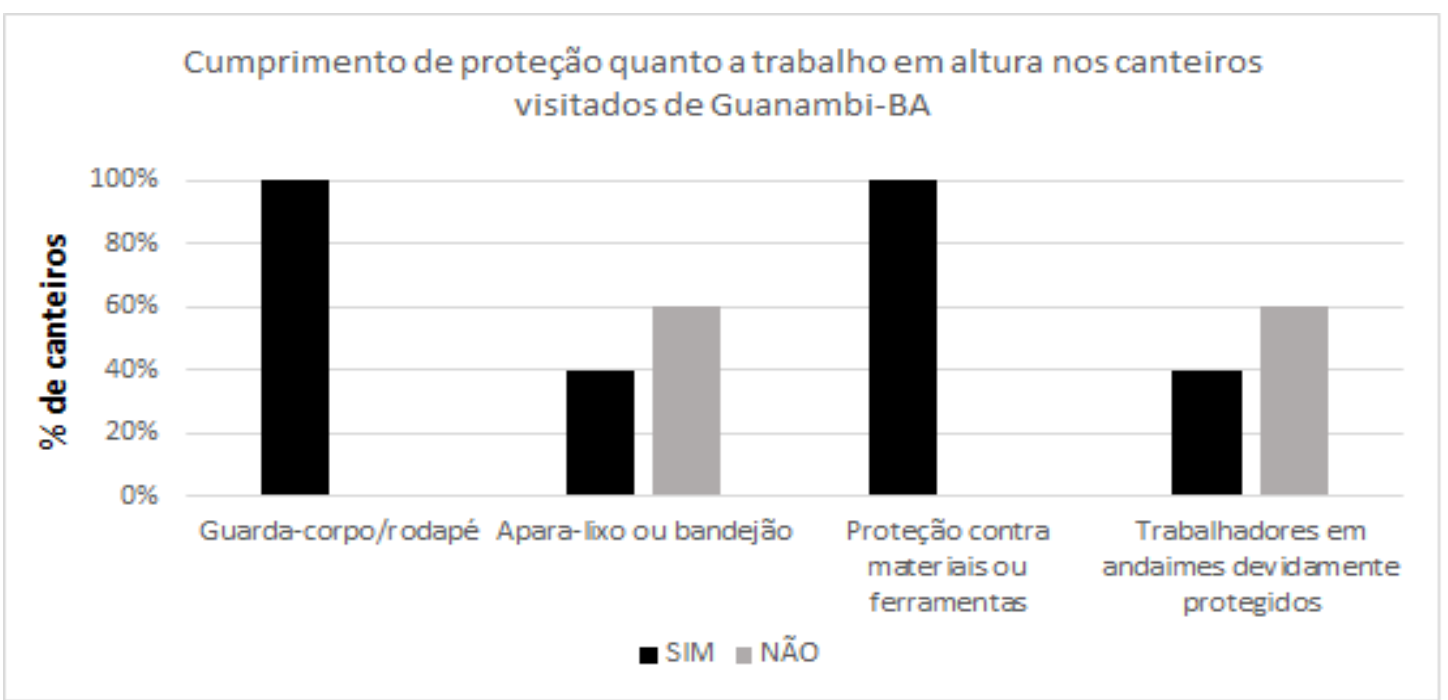

FIGURA 5: Aspectos sobre o cumprimento de proteção quanto a trabalho em altura nos canteiros visitados do município de Guanambi-BA

FONTE: Autoria própria 


\subsubsection{Ocorrência de acidentes de trabalho nos canteiros}

Referente a ocorrência de acidentes de trabalho nos canteiros foi analisada 1 (uma) questão, esquematizada na Tabela 1 , sendo a seguinte:

1- Houve algum acidente de trabalho na obra?

\begin{tabular}{|c|c|}
\hline Variável & $\%$ de canteiros \\
\hline Sim & 20 \\
\hline Não & 80 \\
\hline
\end{tabular}

Fonte: Autoria própria

Foi questionado aos responsáveis técnicos se já havia ocorrido algum acidente de trabalho nas obras visitadas, e em $20 \%$ delas, o que corresponde a 1 (uma) obra, a resposta foi afirmativa. $\mathrm{O}$ acidente ocorrido foi ocasionado por choque elétrico, porém não resultou em morte ou sequelas. De acordo o responsável técnico forneceu-se a devida assistência ao trabalhador, e este encaminhado rapidamente para atendimento médico. Segundo o responsável técnico, foram fornecidos todos os EPIs necessários para o exercício de atividades com risco de choque elétrico, porém, nem todos os trabalhadores os usavam.

\subsubsection{Realização de especialização ou treinamento na área de segurança do trabalho por parte dos responsáveis técnicos dos canteiros visitados}

Referente a realização de especialização ou treinamento na área de segurança do trabalho por parte dos responsáveis técnicos foi analisada 1 (uma) questão, esquematizada na Tabela 2 , sendo a seguinte:

1- Realizou algum treinamento ou especialização na área de segurança do trabalho? Se sim, qual?

\begin{tabular}{cc}
\hline $\begin{array}{c}\text { TABELA 2: Quantidade de responsáveis técnicos } \\
\text { que realizaram especialização ou treinamento na } \\
\text { área de segurança do trabalho nos canteiros } \\
\text { visitados do município de Guanambi-BA }\end{array}$ \\
\hline Variável & \% de responsáveis técnicos \\
\hline Sim & 0 \\
\hline Não & 100 \\
\hline
\end{tabular}

Conforme os dados da tabela, nenhum dos responsáveis técnicos dos canteiros visitados fizeram especialização ou treinamento na área de segurança do trabalho, o que se justifica pela falta de conhecimento deles em alguns itens abordados na pesquisa.

Com isso, percebe-se uma carência dos conhecimentos de segurança do trabalho por parte dos responsáveis técnicos pelos canteiros de obras do município de Guanambi, o que pode acarretar prejuízos à integridade física dos trabalhadores, assim como à produtividade da obra.

\subsection{RESULTADOS OBTIDOS COM OS TRABALHADORES}

Para coleta dos resultados, utilizou-se as variáveis "sim" e "não" com o objetivo de verificar o atendimento aos itens do questionário nos canteiros visitados e tomar conhecimento da realidade dos canteiros por meio da visão dos operários.

\subsubsection{Recebimento de EPIs}

Referente a este item foi analisada 1 (uma) questão, esquematizada na Tabela 3 , sendo a seguinte:

1- Receberam os EPIs necessários para o desempenho das atividades?

\begin{tabular}{cc}
\hline $\begin{array}{c}\text { TABELA 3: Quantidade de trabalhadores que } \\
\text { afirmaram terem recebido os EPIs nos canteiros } \\
\text { visitados do município de Guanambi-BA }\end{array}$ \\
\begin{tabular}{cc} 
\%ariável & \% de responsáveis técnicos \\
\hline Sim & 100 \\
\hline Não & 0 \\
\hline
\end{tabular}
\end{tabular}


Conforme dados da tabela 3 , todos os trabalhadores afirmaram terem recebido os equipamentos de proteção individual (EPIs) pelos responsáveis técnicos para exercício de suas atividades, porém, muitos deles disseram que não os usam pois os acham desconfortáveis e alguns até mesmo prejudicam o desempenho de determinada atividade.

Sendo assim, fica evidente a falta de conscientização e fiscalização por parte dos responsáveis técnicos para que os trabalhadores usem corretamente os EPIs, e até mesmo observar quais são os incômodos causados pelos equipamentos para que possa ser tomada alguma medida, como a troca deles.

\subsubsection{Fiscalização para assegurar as medidas de segurança}

Referente a fiscalização para assegurar as medidas de segurança foi analisada 1 (uma) questão, esquematizada na Tabela 4 , sendo a seguinte:

1- Alguém os fiscaliza para constatar se estão todos de acordo às medidas de segurança?

TABELA 4: Quantidade de trabalhadores que

afirmaram terem sido fiscalizados por algum

profissional para verificação do cumprimento das

medidas de segurança nos canteiros visitados do município de Guanambi-BA

\begin{tabular}{cc} 
Variável & \% de responsáveis técnicos \\
\hline Sim & 90 \\
\hline Não & 10 \\
\hline
\end{tabular}

Conforme a tabela ilustrada, $90 \%$ dos trabalhadores afirmaram que em determinado momento houve fiscalização por parte de algum profissional quanto ao cumprimento das medidas de segurança, enquanto que $10 \%$ dos trabalhadores afirmaram nunca terem sido fiscalizados quanto a isto. A fiscalização foi efetuada pelo Sindicato dos Trabalhadores do município de Guanambi-BA, porém, tendo sido realizada apenas uma visita desde o início das atividades nos canteiros. Além disso, segundo os trabalhadores, um Agente Fiscal da Prefeitura Municipal de Guanambi também já visitou os canteiros realizando fiscalização, porém, apenas uma vez desde o início das atividades.

\section{CONCLUSÕES}

De acordo com o objetivo principal desta pesquisa, analisou-se a realidade das obras de construção civil de canteiros no município de Guanambi-BA, quanto ao cumprimento das normativas no que tange a segurança do trabalhador. Foram aplicados questionários aos responsáveis técnicos e trabalhadores, com vistas a colher informações sobre as condições do ambiente laboral e de como se dá o desenvolvimento do trabalho em questão de segurança.

Os pesquisadores encontraram dificuldades para visitação nos canteiros, visto que, o município possui uma quantidade relativamente pequena de obras regularizadas, e, além disso, alguns responsáveis técnicos não autorizaram as visitas.

Outra dificuldade encontrada foi referente à resistência de alguns empregados em responder aos questionamentos, temendo ser uma pesquisa de cunho trabalhista, geralmente realizada pelos sindicatos, e que poderia prejudicá-los de alguma forma.

A partir dos resultados obtidos, pôde-se notar situações irregulares e falta de conhecimento das normativas de segurança por parte dos responsáveis técnicos, principalmente no que tange o trabalho em altura, onde medidas de proteção coletiva, imprescindíveis para o mantimento da integridade física dos trabalhadores, não foram adotadas.

Constatou-se também que em nenhum dos canteiros foi desenvolvido o PPRA ou PCMAT, programas que visam identificar e avaliar os riscos presentes no ambiente de trabalho para que 
possam ser controlados, o que mostra uma deficiência na gestão destes canteiros quanto a sua segurança e dos trabalhadores presentes pelos responsáveis técnicos.

Muitas das imprudências identificadas nos canteiros do município de Guanambi podem ser explicadas pelo fato de nenhum dos responsáveis técnicos possuir qualquer tipo de especialização ou treinamento na área de segurança, o que justifica várias medidas errôneas e inexistentes que colocam em risco a saúde e segurança de todos os envolvidos.

Porém, também foram constatadas medidas corretas nos canteiros, atendendo o disposto nas normativas vigentes, como a disponibilização de água potável por meio de bebedouros em todos os locais visitados e a presença de áreas de vivência em mais da metade dos canteiros visitados, embora as instalações sanitárias não estivessem em condições higienizadas. Assim como, houve realização de treinamentos admissional e/ou periódico e de EPI em $60 \%$ dos canteiros.

Diante disso, percebe-se que a situação dos canteiros do município de Guanambi-BA apresenta bastantes irregularidades, ainda que tenha se constatado o cumprimento de alguns itens das normas regulamentadoras sobre saúde e segurança no trabalho, porém, muito ainda deve ser feito para que tais ambientes laborais estejam o mais isento possível à ocorrência de eventos danosos à integridade física dos trabalhadores.

Sugere-se aos profissionais responsáveis por esses ambientes de trabalho que procurem se informar mais quanto às normas regulamentadoras e que, se possível, se especializem neste campo, para que se conscientizem da importância de se adotar medidas de segurança em canteiros de obras.

Quanto aos trabalhadores, eles também devem se informar mais quanto aos seus direitos e deveres no que tange a segurança do trabalho, de forma a exigirem medidas protetoras e melhores condições de trabalho, pois são a sua saúde e segurança que estão em risco. Porém, isso ainda é um desafio, visto que a mão de obra atuante nos canteiros é, na maioria dos casos, de baixa escolaridade, e aliando-se esse fato a falta de informações e maior cobrança por parte dos responsáveis técnicos tem-se empecilhos para que os trabalhadores possam se impor e reivindicar melhorias.

Sendo assim, uma medida que pode vir a solucionar este problema é o implemento do Dialogo Diário de Segurança (DDS) nesses ambientes de trabalho, que tem o objetivo de despertar no trabalhador a conscientização envolvendo suas atividades diárias, devendo ser aplicada em um tempo de 5 (cinco) a 15 (quinze) minutos antes do início da jornada de trabalho. Tal ferramenta pode ser executada pelo empregador, membros da Comissão Interna de Prevenção de Acidentes (CIPA), técnico de segurança, ou até mesmo por um funcionário que foi nomeado para realizar esta atividade.

Concomitantemente, deve-se fazer presente a fiscalização compromissada da Prefeitura Municipal e do Sindicato dos Trabalhadores, de forma a garantir o cumprimento das normas regulamentadoras, visando a manutenção de um ambiente de trabalho mais seguro e isento às irresponsabilidades, e garantir a integridade física de todos que exercem suas atividades laborais nos canteiros de obras do município de Guanambi-BA.

\section{REFERÊNCIAS BIBLIOGRÁFICAS}

ASSMANN, C. E. Avaliação do atendimento dos requisitos da NR-18 em canteiros de obras de Santa Rosa. 2015. 85 f. TCC (Graduação em Engenharia Civil) Universidade Regional do Noroeste do Estado do Rio Grande do Sul, Santa Rosa, 2015. Disponível em: http://bibliodigital.unijui.edu.br:8080/xmlui/handle/12 3456789/3407. Acesso em: 06 mai. 2018.

BENITE, A. G. Sistema de gestão da segurança e saúde no trabalho para empresas construtoras. 2004. $221 \mathrm{f}$. Dissertação (Mestrado em Engenharia) - Escola Politécnica da Universidade de São Paulo, São Paulo, $2004 . \quad$ Disponível em: http://www.teses.usp.br/teses/disponiveis/3/3146/tde -27102004-101542/pt-br.php. Acesso em: 03 nov. 2017. 
BRASIL. Lei no 8.213, de 24 de julho de 1991. Dispõe sobre os Planos de Benefícios da Previdência Social e dá outras providências. Diário Oficial da República Federativa do Brasil, Brasília, DF, 25 jul. 1991 Disponível em: http://www.planalto.gov.br/ccivil_03/leis/L8213cons.ht m. Acesso em: 23 mai. 2017.

BRASIL. Lei no 13.429, de 31 de março de 2017. Dispõe sobre o trabalho temporário nas empresas urbanas e dá outras providências; e dispõe sobre as relações de trabalho na empresa de prestação de serviços a terceiros. Diário Oficial da União, Brasília, DF, 31 mar. $2017 . \quad$ Disponível em http://www.planalto.gov.br/ccivil_03/_ato20152018/2017/lei/L13429.htm. Acesso em: 20 fev. 2018.

BRASIL. Ministério da Previdência Social. Informe de Previdência Social: Análise das Estatísticas de Acidentes de Trabalho na Construção Civil. Brasília, 2014, v. 26, n. 7. 43 p. Disponível em: http://www.previdencia.gov.br/wp-

content/uploads/2014/10/Ret_Offset_Informe_julho_2 014.pdf. Acesso em: 23 mai. 2017.

BRASIL. Ministério do Trabalho e Emprego. NR 6: Equipamento de Proteção Individual - EPI. Brasília, $1978 . \quad$ Disponível em: http://trabalho.gov.br/images/Documentos/SST/NR/NR 6.pdf. Acesso em: 11 abr. 2018.

BRASIL. Ministério do Trabalho e Emprego. NR 9: Programa de Prevenção de Riscos Ambientais - PPRA. Brasília, 1978. Disponível em http://trabalho.gov.br/images/Documentos/SST/NR/NR 09/NR-09-2016.pdf. Acesso em: 11 abr. 2018.

BRASIL. Ministério do Trabalho e Emprego. NR 18: Condições e Meio Ambiente de Trabalho na Indústria da Construção. Brasília, 1978. Disponível em: http://trabalho.gov.br/images/Documentos/SST/NR/NR 18/NR18atualizada2015.pdf. Acesso em: 12 abr. 2018.

CAMISASSA, M. Q. Segurança e saúde no trabalho: NRs 1 a 36 Comentadas e Descomplicadas. São Paulo: Método, 2015. 909 p.

COSTELLA, M. F.; JUNGES, F. C.; PILZ, S. E. Avaliação do cumprimento da NR-18 em função do porte de obra residencial e proposta de lista de verificação da NR-18. Ambiente Construído, Porto Alegre, v. 14, n. 3, p. $87-$ 102, jul./set. 2014. Disponível em: http://www.scielo.br/pdf/ac/v14n3/07.pdf. Acesso em: 13 ago. 2017.
DE CARVALHO, R. J. M.; SALDANHA, M. C. W.; SANTANA, C. T.; CAVALCANTE JÚNIOR, P.; PEDROSA, C. D. Condições de trabalho na construção de edificações no triângulo Crajubar-Ce. In: Encontro Nacional de Engenharia de Produção, 18., 1998, Niterói. Anais eletrônicos online. Niterói: ABEPRO, 1998. 6 p. Disponível em: http://www.abepro.org.br/biblioteca/enegep1998_art3 81.pdf. Acesso em: 09 abr. 2018.

DE FARIA, A. F.; GRAEF, G.; SANCHES, J. C. Segurança do trabalho na construção de edificações. In: Simpósio de Engenharia de Produção, 12., 2006, Bauru. Anais eletrônicos online. Bauru: SIMPEP, 2006. p. 1 - 8. Disponível em: http://www.simpep.feb.unesp.br/anais/anais_13/artigo s/1158.pdf. Acesso em: 13 ago. 2017.

DE MÉLO FILHO, E. C.; RABBANI, E. R. K.; BARKOKÉBAS JÚNIOR, B. Avaliação da segurança do trabalho em obras de manutenção de edificações verticais. Produção, São Paulo, v. 22, n. 4, p. 817-830, set./dez. 2012. Disponível em: http://www.prod.org.br/files/v22n4/v22n4a14.pdf. Acesso em: 09 abr. 2018.

FERREIRA, L. S.; PEIXOTO, N. H. Segurança do trabalho I. Santa Maria, RS: UFSM, CTISM, Sistema Escola Técnica do Brasil, 2012. 151 p.

SAURIN, T. A.; RIBEIRO, J. L. D. Segurança no trabalho em um canteiro de obras: percepções dos operários e da gerência. Produção, São Paulo, v. 10, n. 1, p. 05-17, jan./jun. 2000. Disponível em:

http://www.scielo.br/pdf/prod/v10n1/v10n1a01.pdf. Acesso em: 18 mar. 2017.

SILVEIRA, C. A.; ROBAZZI, M. L. do C. C.; WALTER, E. V.; MARZIALE, M. H. P. Acidentes de trabalho na construção civil identificados através de prontuários hospitalares. Revista Escola de Minas, Ouro Preto, v. 58, n. 1, p. 39-44, jan./mar. 2005. Disponível em: http://www.scielo.br/pdf/rem/v58n1/a07v58n1.pdf Acesso em: 23 mai. 2017.

VILELA, R.A.G. Acidentes do trabalho com máquinas: identificação de riscos e prevenção. São Paulo: Central Única dos Trabalhadores, 2000. 34 p. Disponível em:

http://www.coshnetwork.org/sites/default/files/cadern o5\%20maquina.pdf. Acesso em: 02 set. 2017. 